\title{
Application of Mobile - Phone Consultation for Follow-Up of Breast Feeding Continuation in Primiparous Women
}

\author{
P Parsa ${ }^{1, *}$; A Boojar ${ }^{2}$; R Bakht ${ }^{3} ;$ G Roshanaie $^{4}$ \\ 'Associate Professor, Chronic Diseases (Home Care) Research Center, Hamadan University of Medical Sciences, Hamadan, Iran \\ ${ }^{2}$ MSc. Consultation in Midwifery, Atiyeh Hospital, Hamadan, Iran \\ ${ }^{3}$ Ph.D Student, Faculty of Nursing and Midwifery, Hamadan University of Medical Sciences, Hamadan, Iran \\ ${ }^{4}$ Associate Professor, Faculty of Public Health, Hamadan University of Medical Sciences, Hamadan, Iran \\ * Corresponding author: P Parsa, Associate Professor, Chronic Diseases (Home Care) Research Center, Hamadan University of Medical Science, Hamadan, P. O. Box: 6517838678, Iran \\ Tel: +98-8138224396, E-mail: parsa@umsha.ac.ir, pparsa2003@yahoo.com
}

Received: 11 Dec 2016

Accepted: 01 Jan 2017

Epub: 23 Feb 2017

Ppub: 15 Jan 2018

\begin{abstract}
Background: Breastfeeding is one of the most important factors in ensuring the health of infants.

Objectives: The aim of this study was to determine the effect of lactation counseling using a mobile phone on continuation of breast-feeding in primiparous mothers in Hamadan city, Iran, in 2014.

Methods: This study was a randomized clinical trial. In this study, 104 qualified primiparous women, after vaginal delivery, were randomly assigned into 2 intervention and control groups. Before the consultation, a questionnaire included demographic characteristics and continuation of exclusive breast feeding (EBF) was completed by both groups. The 4 weekly sessions during 1 month and 3 mobile phone follow-ups monthly were conducted in the intervention group. While the control group received only routine care. Four months after delivery, the 2 groups were re-examined. Data was analyzed using the independent t-test, paired t-test, and Chi-square test. SPSS version 20 has been used for analyzing the data.

Results: Two groups had no significant differences in demographic variables. Before intervention, there was no significant difference on breastfeeding methods between the intervention and control groups. However, 4 months after the delivery, a significant difference was observed on EBF between the 2 groups $(\mathrm{P}=0.03)$.

Conclusions: With regard to the role of mobile phone consultation for a follow up of breastfeeding continuation, it is suggested that this approach has been used for follow-up of mothers' breastfeeding status.

Keywords: Breastfeeding; Consulting; Primiparous; Mobile Phone
\end{abstract}

